\title{
Sujeito e interdiscurso no universo dialógico da fábula
}

Maria Valíria Aderson de Mello Vargas

Universidade de São Paulo / Universidade Cruzeiro do Sul

\begin{abstract}
RESUMO: O PRESENTE ESTUDO DESTINA-SE À DISCUSSÃO DOS MODOS COMO SE INSTITUEM OS SUJEITOS QUE "DIALOGAM" NOS TEXTOS DE DIFERENTES VERSÕES DA FÁBULA "A GARÇA E O CARANGUEJO", NARRADA NA ÍNDIA ANTIGA, RECRIADA NA FRANÇA POR LA FONTAINE E RETOMADA, EM NOSSO MEIO, POR MONTEIRO LOBATO. NESSA DISCUSSÃO, BUSCA-SE IDENTIFICAR AS RAZÕES QUE CONTRIBUEM PARA A PERMANÊNCIA DA PRÁTICA INTERDISCURSIVA DA FÁBULA, ACENTUADAMENTE MARCADA PELO EMBATE ENTRE FORMAÇÕES DISCURSIVAS DIVERSAS.
\end{abstract}

ABSTRACT: THE AIM OF THIS WORK IS TO DISCUSS HOW THE DIALOGICAL SUBJECTS PARTICIPATE IN THE DIFFERENT VERSION TEXTS OF THE FABLE THE HERON AND THE CRAB, TOLD IN ANCIENT INDIA, RECREATED IN FRENCH BY LA FONTAINE, AND RECOVERED, IN OUR ENVIRONMENT, BY MONTEIRO LOBATO. WE INTEND TO IDENTIFY THE REASONS WHICH ARE RESPONSIBLE FOR THE PERMANENCE OF THE FABLE INTERDISCURSIVE PRACTICE, POINTED OUT BY THE INTERSECTION AMONG DIFFERENT DISCURSIVE FORMATIONS.

PALAVRAS-CHAVE: FÁBULA - PRÁTICAS DISCURSIVAS - SUJEITO - INTERDISCURSO - INTERTEXTUALIDADE KEY-WORDS: FABLE - DISCURSIVE STRATEGIES - SUBJECTIVITY - INTERDISCOURSE - INTERTEXTUALITY 


\section{ntrodução}

O trabalho insere-se num campo mais amplo de discussão das teorias e práticas discursivas, em que se procura verificar as reais possibilidades de estender e aplicar ao ensino de língua portuguesa a análise dos procedimentos de discursivização realizados pelo sujeito na construção de sua imagem e na exposição das crenças e experiências que julga compartilhar com o "outro", ou seja, na prática efetiva da linguagem, reveladora das formações sociais em que o sujeito que a utiliza está inserido.

Predomina, portanto, a idéia de que as novas teorias da linguagem, do texto e do discurso podem ser aplicadas ao universo da educação, em especial no decorrer de atividades didáticas destinadas à prática da leitura e, sobretudo, se, para essas atividades, forem selecionados textos que, embora sejam produzidos em contextos atuais, possibilitam, implícita ou explicitamente, o diálogo com outros textos, situados em tempos e espaços diversos.

Sujeito e interdiscurso na fábula

Para construir a noção de "falante num contexto", conforme argumentam Brown e Yule (1983), é necessário generalizar sobre contextos e determinar as características que os falantes partilham em diferentes contextos; do mesmo modo, para construir a noção de "gênero", é necessário generalizar através de experiências e determinar o que é comum a contos de fadas, a palestras, a poemas épicos etc. Assim, é possível reconhecer um deles como símbolo do tipo generalizado.

Essas noções de "falante" e de "gênero" motivam-nos a analisar comparativamente os textos da tradição indiana e os de La Fontaine que se refletem, ainda, nas fábulas de Monteiro Lobato. Tomamos, aqui, em princípio, a definição de "falante", conforme a apresenta Fiorin (1988), ou seja, como "suporte" de discursos, como produto de relações sociais, que assimila uma ou várias formações discursivas e as reproduz em seu discurso.

Desse modo, procura-se identificar os procedimentos discursivos reveladores de sentidos historicamente construídos, que se perpetuam nos mais diversos dizeres de sujeitos de diferentes épocas e culturas distintas.

A análise dos reflexos do texto indiano nas fábulas de La Fontaine e de Lobato permite, assim, compreender o papel da memória e do interdiscurso nas posições assumidas por sujeitos em textos que, embora se situem bem distantes no tempo e no espaço, aproximam-se no modo de revelar as marcas 
de determinados contextos sociohistóricos e de dar pistas para a compreensão do sentido produzido.

\section{O texto indiano de partida}

A tradição indiana da fábula fundamenta-se nos textos sânscritos da coleção Pañcatantra (Cinco Tratados), que foi compilada por volta do século I d.C. e que se expandiu para o ocidente por meio da versão árabe Calila e Dimna (VIII d.C) e das inúmeras recriações que surgiram a partir desse texto.

Cada um dos cinco livros da coleção compõe-se de uma narrativa-quadro, que se desenvolve por meio da inserção de inúmeras fábulas, intercaladas, originadas umas das outras, para exemplificar ou mesmo justificar as ações dos personagens. São narrativas entremeadas de versos que contêm os preceitos dos códigos de moral e de ética da Índia antiga, principalmente os do famoso Código de Leis de Manu. Por essa razão, muitos estudiosos da cultura indiana definem o Pañcatantra como um verdadeiro tratado sobre a conduta.

As fábulas são narradas pelo brâmane Visnuçarman, para atender ao apelo de um rei, preocupado com a educação dos filhos, que não se devotavam ao aprendizado dos procedimentos adequados à classe guerreira. A "voz" desse narrador mistura-se com as mais diversas "vozes" dos personagens que questionam, narram histórias, lançam preceitos e citam pensamentos e ações de personagens famosos do universo indiano de narrativas. A intenção mais imediata e explícita dessas histórias situa-se, portanto, na busca de despertar nos príncipes o interesse pelo que um ksatriya (representante do poder militar) deve saber: os princípios de conduta na guerra, nos momentos de paz, no tratamento dos subalternos, nas relações com as mulheres e assim por diante. Há, porém, implicitamente, a intenção de colocar em discussão o comportamento humano, de conduzir o leitor/ouvinte dessas histórias e preceitos à análise das próprias atitudes, uma vez que se mostram conseqüências boas ou más, advindas da adoção de procedimentos que envolvem a solidariedade, a união, a ambição, a inveja, a traição, a cupidez, o ódio etc.

Os dois níveis da fábula - o figurativo (a história) e o temático (a moral da história) - apresentam-se no próprio entrelaçar das narrativas, que surgem muitas vezes em decorrência das lições ditadas. Entretanto, ao mesmo tempo 
em que se contam histórias para validar essas lições, apresentam-se outras, cujos conteúdos demonstram que os ensinamentos podem ser questionados, ou seja, que, na prática, prevalecem a esperteza, a inteligência, a perspicácia.

A fábula $A$ garça e o caranguejo, objeto da presente análise ${ }^{1}$, insere-se na narrativa-quadro do primeiro livro da coleção, intitulado $A$ desunião de amigos. Ali se apresenta a história de dois chacais, Karataka e Damanaka, ministros da corte, que vão promover a inimizade entre o leão (o rei) e o touro (ministro de confiança do rei). Karataka provoca Damanaka, argumentando que este não era forte o bastante para dominar o touro e o leão, dotados de força e inteligência. Damanaka, então, para provar que mesmo o fraco pode vencer o forte, conta ao amigo a fábula $O$ casal de corvos e, dentro dessa nova narrativa, um chacal, buscando demonstrar que pela esperteza, mais que pelas armas, se vence um inimigo, diz ao casal de corvos: Por avidez excessiva, depois de comer muitos peixes grandes, pequenos e médios, uma certa garça foi morta no abraço de um caranguejo. ${ }^{2}$

Os corvos perguntam: "Como foi isso?" O chacal, então, narra:

Havia, numa certa provincia, um lago habitado por diversos animais aquáticos. Lá encontrou refúgio uma garça que chegara à senilidade e se tornara incapaz de apanhar peixes. E então, com a garganta ressecada pela fome, postando-se à margem do lago, chorou, regando o solo com rios de lágrimas que pareciam montes de pérolas dispersas.

Condoído por essa dor, um caranguejo, que estava acompanhado de alguns habitantes do lago, aproximou-se e, com respeito, disse à garça:

- Minha cara, por que hoje você não se dá ao trabalho de buscar comida? Permanece aí, apenas com suspiros e olhos lacrimejantes!

- Filho, ela respondeu, você percebeu a verdade: de fato, agora faço jejum, e aqui permaneço à espera da morte, com extremo desapego pela alimentação, de modo que eu não como nem mesmo os peixes que se aproximam.

Ouvindo isso, o caranguejo perguntou:

- Amiga, qual a causa desse desapego?

- Filho, explicou ela, eu nasci e cresci neste lago. Ouvi dizer, entretanto, que uma estiagem de doze anos está na iminência de acontecer.

1 Essa e mais duas fábulas prestam-se ao estudo que se promove no artigo Reflexos da fábula indiana nos textos de Monteiro Lobato, publicado na revista Magma, n. 2, p. 74-87, 1995.

2 Os textos do Pañcatantra que aqui se apresentam figuram no primeiro volume de Pañcatantra. Fábulas Indianas - Livro I (2004). 
- De quem você ouviu isso? - perguntou o caranguejo.

- Da boca de um vidente, disse a garça, [...] este é um lago que tem muito pouca água. Logo ficará seco. Quando isso ocorrer, todos aqueles junto aos quais eu cresci e com quem sempre brinquei morrerão por falta de água. Por isso, eu sou incapaz de assistir à separação deles. Assim, faço jejum, aqui parada à espera da morte. Neste momento, os animais aquáticos de todos os pequenos lagos são levados para os grandes lagos por seus próprios parentes. E alguns crocodilos, gaviais, delfins, elefantes marinhos e outros vão por si mesmos. Aqui no lago, ao contrário, os habitantes estão despreocupados, por isso eu choro pela espécie, já que não restará nem um só como semente.

Tendo ouvido isso, o caranguejo foi contar aos companheiros a bistória da garça.

Ai os peixes, as tartarugas e os outros animais, todos eles trêmulos de medo, aproximaram-se dela e perguntaram:

- Amiga, existe algum meio pelo qual possamos salvar-nos?

A garça disse:

- Há, não muito longe deste lago, uma lagoa que contém água abundante, adornada com muitos lótus, e que não ficará seca nem mesmo com vinte e quatro anos de estiagem. Se alguém montar no meu dorso, eu o conduzo até lá.

- Ai, com confiança, eles exclamaram:

- Amiga! Tia! Irmã! Primeiro eu! Primeiro eu!

E rodearam-na por todos os lados. Ela, um poço de maldade, fazendo-os subir no dorso, um a um, ia até uma rocha não muito longe do lago. Lá os arremessava contra a rocha e os comia à vontade. Depois, voltando ao lago, ludibriava os remanescentes com notícias e mensagens falsas. Fazia isso cotidianamente, como modo de subsistência.

Certo dia, o caranguejo disse:

- Minha cara, foi comigo que aconteceu a sua primeira conversa de amigo. Por que, então, você me abandona e leva os outros? Por isso, hoje, providencie minha salvação.

Ouvindo isso, mal intencionada, ela pensou:

- Estou mesmo enjoada de alimentar-me de peixe. Hoje, então, preparo esse caranguejo como condimento.

Depois de assim refletir, ajudou-o a subir no dorso e partiu na direção do rochedo da morte. O caranguejo, porém, observando de longe a montanha de ossos junto à rocha e percebendo que eram ossos de peixe, perguntou-lhe:

- Amiga, a que distância está o lago? Você está muito cansada com o meu peso? Diga-me.

Ela pensou: "Este animal aquático é um débil mental mesmo; não se sustenta em terra firme." Sorrindo, então respondeu: 
- Caranguejo! O lago, onde? Este é meu modo de subsistência. Por isso, recorde-se de sua divindade predileta. Vou arremessá-lo naquela rocha e comê-lo.

Enquanto ela assim falava, foi prensada no delicado pescoco, branco como um talo de lótus, pelas duas presas da boca do caranguejo e foi morta. Em seguida, ele tomou o pescoco da garça e aproximou-se do lago vagarosamente. Então, os companheiros perguntaram-lhe:

- Ó caranguejo! Por que você retornou? Há uma boa razão? A garça não veio. Por que demora? Todos estamos à espera, ansiosos e impacientes.

Quando eles assim falaram, o caranguejo, caindo na risada, disse:

- Estúpidos! Todos os companheiros foram enganados, arremessados contra uma rocha não muito distante e comidos por aquela mentirosa. Mas, como ainda não chegou a minha hora fatal, percebi a intenção daquela traidora e aqui trago o seu pescoço. E chega de confusão! Agora haverá tranqüilidade para todos.

- Por isso, eu digo:

Por avidez excessiva, depois de comer muitos peixes grandes, pequenos e médios, uma certa garça foi morta no abraço de um caranguejo.

Depois disso, a narrativa sobre o casal de corvos é retomada.

É interessante notar, no modo como se estrutura o discurso persuasivo da garça, a intencionalidade de quem conta a história. Revela-se, num primeiro plano, um narrador que insere a fábula na história dos dois chacais, narrada com o propósito de educar os príncipes. Manifesta-se, também, como narrador, o chacal que busca convencer o outro por meio da história do casal de corvos e, ainda, um novo narrador que se serve da história da garça e do caranguejo para convencer o casal de que o fraco pode vencer o mais forte. Além disso, há o narrador universal, intemporal, instaurado na fábula propriamente dita, aquela que o povo conta. Ou seja, há um emaranhado de narrativas e de narradores que pressupõem narratários também em vários planos: os príncipes, o chacal, o casal de corvos, os leitores/ouvintes de todas as histórias.

A interlocução que se promove na narrativa não se configura, portanto, apenas como forma de veicular conhecimento, mas, sobretudo, como estratégia para permitir a cooperação e a disposição ativa do leitor/ouvinte no propósito de construção do sentido do texto.

O emprego incessante do discurso direto nessas narrativas reforça o tom de conversa e tende a revelar mais fielmente a situação de enunciação. Do mesmo modo são marcas enunciativas e, sobretudo, discursivas, certas expressões 
dialógicas que denunciam o envolvimento de outros sujeitos na constituição da fábula, como é o caso de "por isso eu digo", predominante no Pañcatantra.

Torna-se, assim, muito evidente a intencionalidade do emissor nessas fábulas; os meios que emprega na elaboração do discurso para alcançar seu objetivo são claramente revelados ao leitor/ouvinte e isso certamente contribui para a aceitabilidade dos argumentos. Essa organização discursiva certamente contribui para a permanência dessas histórias, que se reproduzem e se adaptam aos diversos meios em que se inserem.

\section{A fábula de La Fontaine: intertexto e interdiscurso}

As Fábulas de La Fontaine (1621-1695), escritas em versos, apresentam-se distribuídas em doze livros, dos quais, os de números VII a XI formam a segunda coleção de fábulas, inspiradas, de acordo com o próprio autor, no "sábio indiano Pilpay".

A fábula Os peixes e o alcatraz, na tradução de Milton Amado e Eugênio Amado (1989 233-236), assim se apresenta:

Não havia lagoa ali nas redondezas

que por certo alcatraz não fosse tributada.

Pagavam-lhe pensão viveiros e represas.

De cozinha ia bem; mas a idade avançada

veio alquebrá-lo, e o pobre do animal

de cozinha passou a ir muito mal.

Todo alcatraz sempre é provedor de si mesmo.

Este, já um tanto velho para ver

o fundo da água, sem caniço ou rede ter,

podendo só tentar pescarias a esmo,

sofria privações extremas.

Mas a necessidade em mil estratagemas

é doutora e um the deu. Tendo ele o ensejo

de encontrar junto a um charco um caranguejo,

diz-lhe: - "Compadre, vai depressa, neste instante,

a esse povo levar um aviso importante. 
Ele está condenado a morrer, pois pescar aqui em breve virá o dono do lugar". O caranguejo parte em disparada e conta o caso; far-se imensa atoarda.

Correm, discutem, mandam embaixada ao alcatraz: - Senhor, noticias tais de onde vos vêm? Em que vos baseais? Tendes plena certeza? A morte nos aguarda?

De um recurso sabeis? Dizei-nos, que faremos?"

- "Mudai de habitação". - "Faz̧elelo não podemos".

- "Não temais. Livrarei a todos do perigo levando um após o outro ao meu abrigo.

Só Deus e eu saberemos chegar lá. A própria natureza o quis cavar com suas mãos e ocultá-lo. Em tal viveiro desconbecido do homem traiçoeiro, vossa república há de estar em paz". Crê nele o povo aquático e é levado, um por um, para pouco freqüentado lugar sob uma rocha, onde o alcatraz. bom apóstolo, os deixa em raso e claro recanto, de água cristalina e escassa, e onde a apanhá-los sem esforço passa, um hoje, outro amanhã. Custou-lhes caro aprender que jamais é possivel confiar em quem vive de os outros devorar. A verdade é, porém, que fatalmente coisa igual lhes faria a humana gente.

Que importa se vos vem lobo ou homem comer? Qualquer ventre, para isso, o mesmo me parece. Coma agora ou depois, retarde-se ou se apresse, tão grande diferença isso não vai fazer. 
É clara a intenção de La Fontaine de utilizar a fábula como uma advertência, uma crítica social. Taine (s.d.) reconhecia, nessa fábula, as aflições do povo, marcado pela desordem de espírito e pressionado; pessoas pobres, mas não pouco políticas, como argumenta o estudioso francês, feitas para serem "devoradas" e que provam isso abundantemente por suas ações. Isso se evidencia nos versos:

\section{Correm, discutem, mandam embaixada ao alcatra:: - Senhor, notícias tais de onde vos vêm? Em que vos baseais? Tendes plena certeza? A morte nos aguarda? De um recurso sabeis? Dizei-nos, que faremos?}

Explicita-se, no texto de La Fontaine, a intertextualidade, por meio de idéias que o leitor/ouvinte reconhece no apelo aos ditos populares: "Todo alcatraz. sempre é provedor de si mesmo", "Mas a necessidade em mil estratagemas é doutora", "... jamais é possivel confiar / em quem vive de os outros devorar".

Isso remete às ideias de Maingueneau (2004) sobre a "sabedoria popular". Essa seria, na realidade, a própria comunidade dos locutores de uma língua; cada locutor é indiretamente um dos membros dessa instância. Essa filiação, contudo, só pode ser indireta, pois a sabedoria popular transcende os locutores reais, provém dos mais remotos tempos, de uma experiência imemorial.

A fábula não se presta a simplesmente veicular uma moral, ou um ensinamento. Vai além, porquanto alerta para a intenção de domínio do mais forte e para a forma de prevenir-se dessa intenção. No texto de La Fontaine, aliás, o fabulista parece planejar o afastamento de qualquer moralidade. Enquanto no texto indiano há uma lenta construção da intencionalidade de alertar o leitor/ ouvinte, no de La Fontaine esse alerta se dá mais direta e rapidamente:

\footnotetext{
Que importa se vos vem lobo ou homem comer?

Qualquer ventre, para isso, o mesmo me parece.

Coma agora ou depois, retarde-se ou se apresse,

tão grande diferença isso não vai fazer.
} 
Reconhece-se, no texto de La Fontaine, em relação à fábula indiana, o que Schaeffer (1985) denomina "généricité hypertextuelle à projection d'origine". O fabulista mostra-se, sem cessar, entre a obrigação de fidelidade ao modelo e a consciência de sua própria inventividade e de seus próprios méritos. Essa relação hipertextual, conforme argumenta Schaeffer (1985), consiste numa espécie de adição genérica e não numa transformação, pois La Fontaine, na verdade, reproduz os traços do modelo indiano, adaptando-o a suas intenções.

O texto indiano, por sua vez, possui, em relação ao texto de La Fontaine, a função de "legitimação ideológica" (SCHAEFFER, 1985: 354), que assim se explica: não é o texto do Pañcatantra que legitima o de La Fontaine, mas é a prática discursiva da fábula indiana que legitima a mesma escolha feita por La Fontaine. A legitimação dessa prática discursiva influi evidentemente sobre o estatuto ideológico do texto de La Fontaine, que, por sua vez, também influencia o texto anterior, já que com este passa a "dialogar".

A fábula, portanto, requer do leitor/ouvinte um conhecimento expressivo das normas de conduta, dos códigos de leis, no caso do leitor indiano, e também um profundo conhecimento dos problemas da sociedade, especialmente a francesa do século XVII, no caso do leitor de La Fontaine.

É preciso reconhecer nesses textos as características de comunicação textual que, de acordo com Beaugrande e Dressler (1981), constitui o sistema mais elaborado e sutilmente diferenciado do comportamento humano, já que essa comunicação vincula todas as habilidades maiores - resolver problemas, planejar, revisar hipóteses etc. - e o proveito de sua leitura implica, sobretudo, a habilidade de aplicar ou adaptar certa disposição de modelos e de procedimentos adequados a uma determinada situação.

\section{Reflexos da fábula indiana no texto de Lobato: sujeitos em interação}

O texto indiano reflete-se também na fábula $A$ garça velha, de Monteiro Lobato (1922), inspirada em La Fontaine:

Certa garça nascera, crescera e sempre vivera à margem duma lagoa de águas turvas, muito rica em peixe. Mas o tempo corria e ela envelhecia. Seus músculos cada vez mais emperrados, os olhos cansados - com que dificuldade ela pescava!

- Estou mal de sorte, e se não topo com um bom viveiro de peixes em águas bem limpi- 
das, certamente que morrerei de fome. Já se foi o tempo feliz. em que meus olhos penetrantes zombavam do turvo desta lagoa...

E de pé num pé só, o longo bico, pendurado, pôs-se a maturar naquilo até que lhe ocorreu uma idéia.

- Caranguejo, venha cá! - disse ela a um caranguejo que tomava sol à porta do seu buraco.

- As ordens. Que deseja?

- Avisar a você duma coisa muito séria. A nossa lagoa está condenada. O dono das terras anda a convidar os vizinhos para assistirem ao seu esvaziamento e o ajudarem a apanhar a peixaria toda. Veja que desgraça! Não vai escapar nem um miserável guaru.

O caranguejo arrepiou-se com a má notícia. Entrou na água e foi contá-la aos peixes.

Grande rebuliço. Graúdos e pequeninos, todos começaram a pererecar às tontas, sem saberem como agir. E vieram para a beira d'água.

- Senhora dona do bico longo, dê-nos um conselho, por favor, que nos livre da grande calamidade.

- Um conselho? ... e a matreira fingiu refletir. Depois respondeu. Só vejo um caminho. É mudarem-se todos para o poço da Pedra Branca.

- Mudar-se como, se não há ligação entre a lagoa e o poço?

- Isso é o de menos. Cá estou eu para resolver a dificuldade. Transporto a peixaria inteira no meu bico.

Não havendo outro remédio, aceitaram os peixes aquele alvitre - e a garça os mudou a todos para o tal poço, que era um tanque de pedra, pequenino, de águas sempre límpidas e onde ela sossegadamente poderia pescá-los até o fim da vida.

Ninguém acredite em conselho de inimigo.

Na obra de Lobato, apresenta-se um cenário de serões em que se delega a Dona Benta o papel de narradora de um universo de fábulas, por ela definidas como lições de moral. Aos demais participantes desses serões, personagens do Sítio do Pica-pau Amarelo, não cabe apenas ouvir e assimilar as histórias, mas também transportá-las para a discussão de ações e comportamentos que caracterizam a realidade daquele momento e daquele espaço. Revelam-se, nessas discussões, o ponto de vista da criança, representada por Narizinho e Pedrinho, e o de personagens de inteligência aguçada, o Sabugo e a Boneca de pano. $\mathrm{O}$ fabulista deixa as personagens dialogarem de maneira autônoma. Nesse processo, o destinatário/espectador/leitor identifica-se, deixa-se im- 
pressionar, reconhece-se como co-participante das variadas situações representadas, que se caracterizam como simulações da realidade.

Nos comentários a respeito de cada fábula narrada é que se encontram os elementos que mais a aproximam, quanto ao conteúdo e à estrutura textual, do modelo das fábulas do Pañcatantra. Os textos projetam-se na visão de cada um dos ouvintes que opina sobre a fábula. A da garça velha provoca a seguinte discussão, no universo do Sítio do Pica-pau Amarelo:

- Eu não acredito nem em conselhos de amigos quanto mais de inimigos - disse Emilia. Não quero que aconteça o que aconteceu com o coronel Teodorico.

Ninguém entendeu. Emília explicou:

- Ele foi para o Rio de Janeiro depois da venda das terras e acabou sem vintém. Por quê? Porque acreditou nos conselhos dos amigos do seu dinheiro. Até bondes o burrão comprou! Eu, quando me dão algum conselho, fico pensando comigo mesmo: "Onde é que está o gato?" Porque há sempre um gato escondido dentro de cada conselho.

Dona Benta arregalou os olhos. Como estava ficando sabida aquela diabinha.

- E em que você acredita, então? perguntou o visconde.

Emilia respondeu:

- No meu miolo. Não vou em onda nenhuma, nem de inimigo nem de amigo. Cá comigo é ali na batata do cálculo.

Esses comentários parecem justificar a mudança que Lobato promove no texto que lhe serviu de modelo. Não se dá no novo texto o castigo da garça. Os comentários, certamente, seriam outros, se Lobato também optasse por utilizar essa fábula para demonstrar que o fraco pode vencer o forte. Ou seja, para servir, em determinado momento, aos propósitos de Lobato, principalmente o de discutir os problemas sociais de sua época, tendo em vista a formação, já na criança, do raciocínio e do julgamento, envolvem-se, no novo texto, outros narradores, outros personagens, outros temas; recria-se, portanto, a fábula.

\section{Considerações finais}

Nas diferentes versões da fábula indiana, revelam-se, como se procurou mostrar, sujeitos em constante diálogo com outros sujeitos, que, embora se 
situem em épocas e culturas distantes, compartilham, com aqueles, traços universais do comportamento humano.

Analisar os efeitos de sentido provocados por esse diálogo é buscar as condições sociohistóricas em que os textos se manifestam, é reportar-se à memória, ao interdiscurso, é, enfim, compreender por que são ditos e reconhecer as peculiaridades dos mais variados modos de dizer.

Por meio da prática discursiva da fábula, revelam-se, enfim, sentidos historicamente construídos que se perpetuam, convém insistir, nos mais diversos dizeres de sujeitos de diferentes épocas e culturas distintas.

\section{Referências Bibliográficas}

BEAUGRANDE, Robert-Alain; DRESSLER, Wolfgang. Introduction to Text Linguistics. New York: Longman, 1981.

BROWN, Gillian; YULE, George. Discourse Analysis. New York: Cambridge University Press, 1983.

FIORIN, José Luiz. Linguagem e ideologia. São Paulo: Ática, 1988.

LA FONTAINE. Fábulas de La Fontaine, v. II. Trad. Milton Amado e Eugênio Amado. Belo Horizonte: Itatiaia, 1989.

MAINGUENEAU, Dominique. Do provérbio à ironia: polifonia, captação e subversão. In: Análise de textos de comunicação. Trad. C.P. de Souza-e-Silva e Décio Rocha. 3. ed. São Paulo: Cortez, 2004, p. 169-178.

PAÑCATANTRA. Fábulas indianas - Livro I. Trad. do sânscrito para o português, por Maria da Graça Tesheiner, Marianne Fleming e Maria Valíria Aderson de Mello Vargas. 2. ed. São Paulo: Humanitas; FFLCH/USP, 2004 [1. ed. 2003].

SCHAEFFER, Jean-Marie. Du texte au genre. Notes sur la problématique générique. Poétique, Paris: Seuil, v. 53, p. 3-18, fev. 1983.

. Aesopus auctor inventus. Naissance d'un genre: La fable ésopique. Poétique, Paris: Seuil, v. 83, p. 345-364, 1985.

TAINE, H. La Fontaine et ses fables. 29. ed. Paris: Hachette, s.d. 